\title{
Correction to: A Bird's Eye View on Sustainable Management Solutions for Non-degradable Plastic Wastes
}

Gopal Jeya, Sridharan Rajalakshmi, Krishnaswamy Veena Gayathri, Ponmudi Priya, Pachagounder Sakthivel, and Vajiravelu Sivamurugan

\section{Correction to:}

Chapter 20 in: M. Vasanthy et al. (eds.), Organic Pollutants, Emerging Contaminants and Associated Treatment Technologies, https://doi.org/10.1007/978-3-030-72441-2_20

The original version of this chapter was inadvertently published without updating the Figs. 1 (Pg-507) and 2 (Pg-509) as per the author's request. Although they are correctly present on the online version.

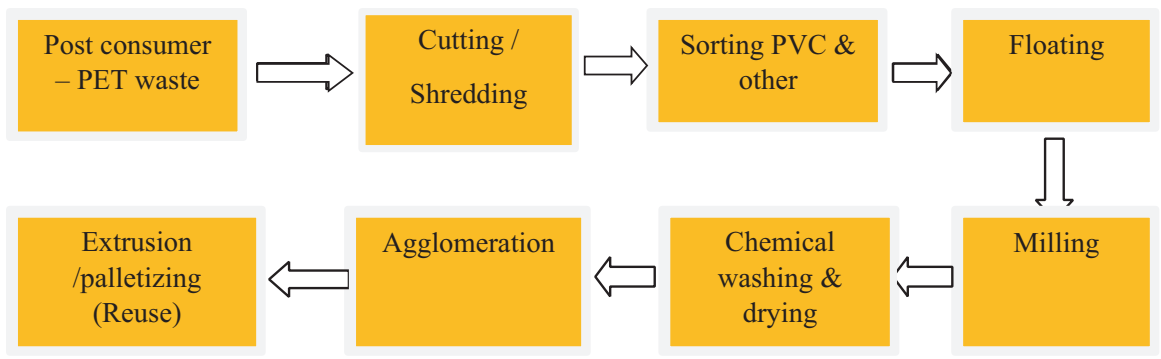

Fig. 1 Mechanical recycling methods

The updated version of this chapter can be found at https://doi.org/10.1007/978-3-030-72441-2_20 


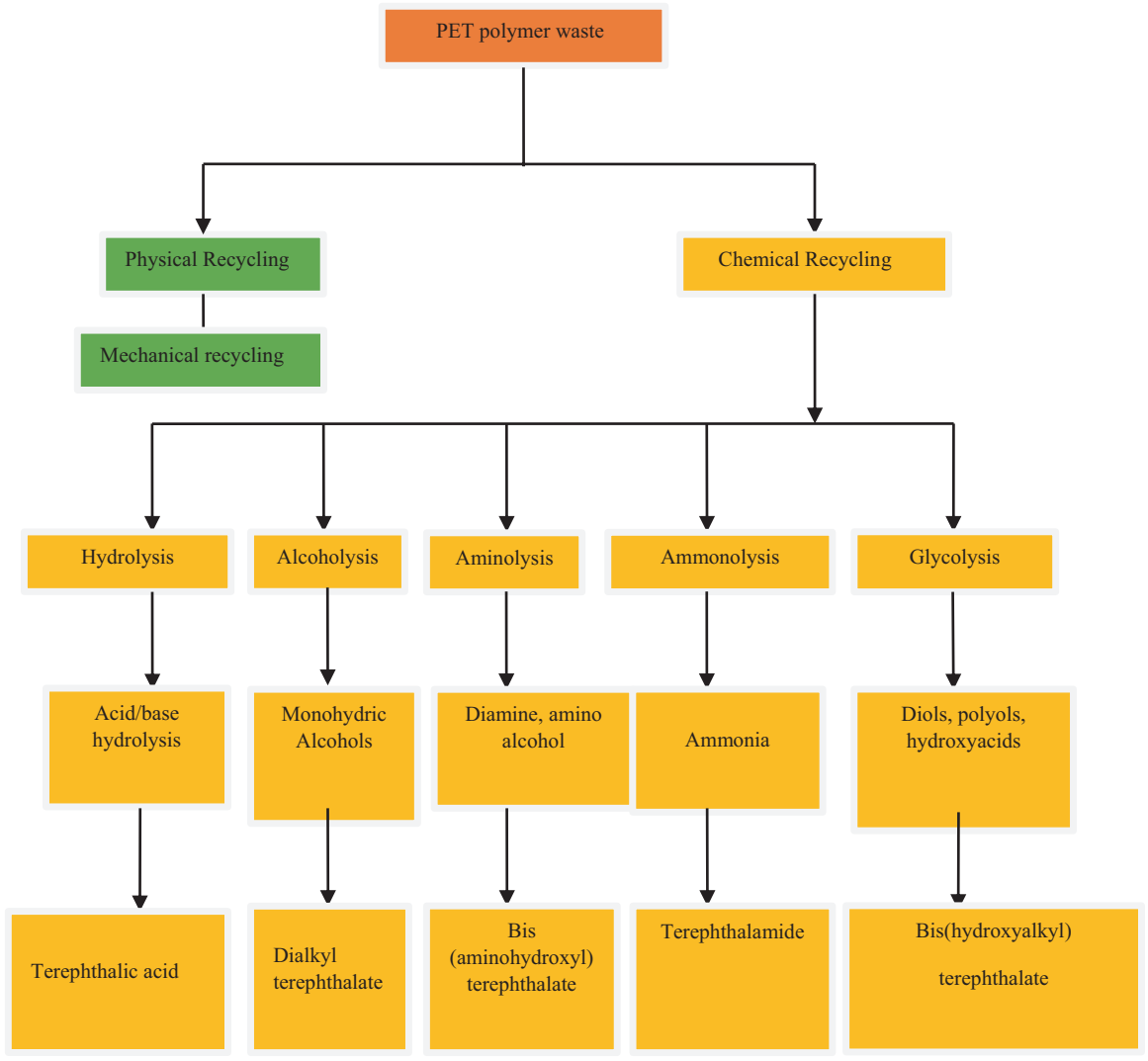

Fig. 2 Recycling methods of PET polymer wastes recycling method 